\begin{tabular}{|l|l|}
\hline Vigencia de Agustín Cueva en la era de la contrarrevolución neoliberal & Titulo \\
\hline Harispuru López, Ricardo - Autor/a; & Autor(es) \\
\hline $\begin{array}{l}\text { De Raíz Diversa. Revista Especializada en Estudios Latinoamericanos (Vol. 3 no. 5 } \\
\text { ene-jun 2016) }\end{array}$ & En: \\
\hline Ciudad de México & Lugar \\
\hline $\begin{array}{l}\text { Programa de Posgrado en Estudios Latinoamericanos, Universidad Nacional } \\
\text { Autónoma de México }\end{array}$ & Editorial/Editor \\
\hline 2016 & Fecha \\
\hline $\begin{array}{l}\text { Imperialismo; Cueva, Agustín; Pensamiento único; Explotación; Neoliberalismo; } \\
\text { Contrarrevolución; América Latina; }\end{array}$ & Colección \\
\hline Artículo & Temas \\
\hline $\begin{array}{l}\text { "http://biblioteca.clacsoedu.ar/Mexico/ppel-unam/20160630025626/3__Vigencia_de_Agustin_Cueva_en_la_era_de_la_contrarrevolucion__ } \\
\text { neoliberal_Ricardo_Harispuru_Lopez.pdf" }\end{array}$ & URL \\
\hline $\begin{array}{l}\text { Reconocimiento-No Comercial-Sin Derivadas CC BY-NC-ND } \\
\text { http://creativecommons.org/licenses/by-nc-nd/2.0/deed.es }\end{array}$ & Licencia \\
\hline
\end{tabular}

Segui buscando en la Red de Bibliotecas Virtuales de CLACSO http://biblioteca.clacso.edu.ar

Consejo Latinoamericano de Ciencias Sociales (CLACSO)

Conselho Latino-americano de Ciências Sociais (CLACSO)

Latin American Council of Social Sciences (CLACSO)

www.clacso.edu.ar

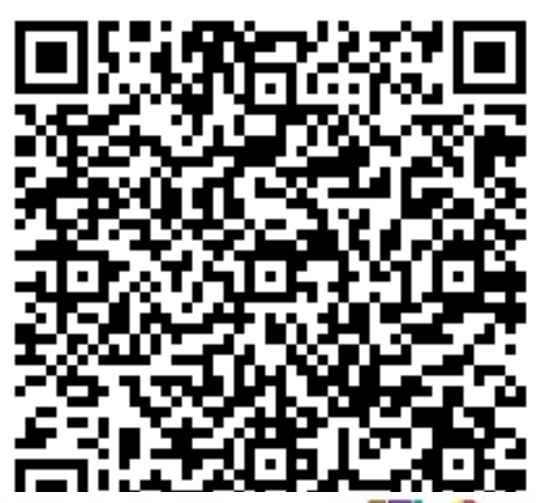

Consejo Latinoamericano de Ciencias Sociales

Conselho Latino-americano de Ciências Sociais 


\title{
Vigencia de Agustín Cueva en la era de la contrarrevolución neoliberal
}

\author{
RICARDO HARISPURU LÓPEZ ${ }^{*}$
}

Resumen: El artículo revisa la respuesta de Agustín Cueva en torno a la cruzada conservadora desarrollada desde los años ochenta. A los ojos del ecuatoriano, esta cruzada constituye una de las tantas fuerzas integradas a lo que él llamó la contrarrevolución política, militar, económica, ideológica, cultural y ética del imperialismo. La aportación de Agustín Cueva resulta necesaria para comprender el ascenso neoliberal en América Latina, así como su embestida contra la visión y las herencias revolucionarias.

Palabras Clave: Contrarrevolución, neoliberalismo, explotación, pensamiento único.

ABstract: This article reviews the response of Agustín Cueva in relation to the conservative crusade developed since the nineteen eighties. To the eye of the Ecuadorian, this crusade constitutes one of the many integrated forces to which he named the political, military, economic, ideological, cultural and ethical counterrevolution of the imperialism. Agustín Cueva's contribution is necessary for the comprehension of the neoliberal rise in Latin America, as well as its lunge against vision and revolutionary inheritance.

KEYWORDS: Counterrevolution, neoliberalism, exploitation, single thought.

Recibido: 10 de septiembre de 2015. ACEPTAdo: 28 de octubre de 2015 .

La afirmación de que la historia no puede repetirse es una de esas verdades

a medias... Es cierto que la historia nunca se repite "al pie de la letra", mas ello no impide que exista un cierto número de regularidades estructurales, $y$ por lo tanto de "repeticiones" que no son más que expresión de las leyes que rigen la conformación, el funcionamiento y el desarrollo de cada modo determinado de producción.

Agustín Cueva (2009a: 65)

Doctorante en el Posgrado en Estudios Latinoamericanos de la UNAM, <rharispuru55@ yahoo.com.mx>. 


\section{$\mathrm{N}$}

o pretendemos mantener aquí ni archivar el pensamiento de Agustín Cueva como pensamiento fustigador de la teoría de la dependencia, aunque ciertamente lo fue; más bien, pretendemos sacarlo a partir del desconcierto o la sorpresa que experimentó al ver que su crítica a dicha teoría, desarrollada en los años setenta, se sumó contra su voluntad "al aluvión derechista" de los ochenta (Cueva, 2008: 203), y que, formalizado como pensamiento sustituto de aquélla, ocupó posición direccional y hegemónica en las academias, en las editoriales, en el ambiente conceptual y en el análisis político, encargándose, de esta manera y como lo señala él mismo, del desmantelamiento de la visión que durante el siglo xx construyó la izquierda revolucionaria en torno a Latinoamérica (Cueva, 2012b: 184).

Con este solo testimonio concerniente a la cruzada neoconservadora contra el pensamiento crítico latinoamericano, proponemos recuperar la respuesta de Cueva y cotejarla ante una forma de realidad social que tampoco resultaría impertinente analizarla hoy bajo la óptica teórica de la neodependencia. Y aunque este no será nuestro marco conceptual a utilizar, y dejaremos por lo pronto aquí mencionada la cuestión del aluvión derechista para abordarla más adelante, debemos decir antes que, para Cueva, ésta no emergió aislada sino integrada a un fenómeno estructural y global que, en 1988, el ecuatoriano lo calificó como contrarrevolución política, militar, económica, ideológica, cultural y ética del imperialismo (Cueva, 2012c: 161).

Y si bien, la amplitud del fenómeno contrarrevolucionario queda por sí sola anunciada, lo que nos interesa más que nada es precisar su concepto, y para ello, habría que retomar de Agustín Cueva la ruta metodológica que entregó al pensamiento latinoamericano en octubre de 1989 -semanas antes del derrumbamiento del Muro de Berlín-, específicamente en su posfacio de El desarrollo del capitalismo en América Latina. Ahí, y ante la crisis derivada de la propia contrarrevolución, "crisis de alta intensidad", Cueva describe la derechización estructural e integral, que respondía a la toma de poder de numerosos gobiernos neoliberales, incluidos los de la Europa occidental y el Japón; a la aplicación "de un darwinismo puro y duro" por parte del mercado sobre la reorganización empresarial de la economía; a la cruzada ideológica y reaccionaria, encargada en revalorizar intelectualmente el capital y la propiedad privada; al control estadounidense sobre la producción y circulación global de contenidos mediáticos, cinematográficos y musicales; y finalmente, al "conservadurismo de ma- 
sas" o ese "sentido común conservador que... convierte a la nueva derecha en una fuerza avasalladora, capaz de llevar adelante una verdadera cruzada reaccionaria a nivel mundial". (Cueva, 2009a: 244-258).

Tras la inminente y prevista caída del Muro y por lo tanto del bloque soviético, el advenimiento de esta ofensiva multilateral pero igualmente asimétrica, destinada a proyectar intensidades diversas de violencia, estaba puesto por Cueva en términos de expansionismo y dominación global, ante lo cual, su diagnóstico indicaba que el proceso de derechización conduciría eventualmente: [1] a la ramificación mundial de Estados neoliberales; [2] a la agudización de las contradicciones sociales y de clase; [3] a la dirección hegemónica del pensamiento conservador en las ciencias, en las artes, en las escuelas, universidades, y otras áreas de producción de conocimiento; [4] a la presencia espontánea y cotidiana en la vida social del capitalismo discursivo, simbólico y cultural, atribuida al bombardeo de contenidos diseñados, controlados y distribuidos por los conglomerados del entretenimiento, la publicidad y la comunicación; [5] y a la reproducción y normalización de un sentido común justificador o defensor de todo lo anterior.

El embate contrarrevolucionario proyectaba que el éxito de sus campañas 1 y 2 produciría el marco jurídico necesario para agudizar las contradicciones lucrativas del capital, al tiempo en que un sistema valorativo, producido por las campañas 3 y 4 , iría ideologizando la interpretación de aquéllas al punto de propiciar, como campaña 5, la tutela, la resignación o la enajenación social ante éstas, hasta conseguir que los estados neoliberales, la violencia económica, el pensamiento conservador y los medios de comunicación fuesen social y hegemónicamente apreciados, absoluta o relativamente, como referentes de la democracia, la prosperidad, la vanguardia y la libertad de expresión.

Viéndolo así, el proceso de derechización que diagnosticó Cueva resultaba ser un proceso de definición civilizatoria, en la que las diversas respuestas sobre qué producimos las personas, cómo sobrevivimos, qué pensamos y valoramos estarían de un modo u otro asediadas y cercadas por la contrarrevolución de la derecha y sus violencias. Por ello, la lectura de Agustín Cueva contenía implícitamente una advertencia sobre la degradación simultánea de la vida tanto objetiva como subjetiva. Y porque esta advertencia no resulta ser sino una hipótesis lanzada desde los tiempos de Cueva hacia la realidad social actual, nuestro propósito aquí es comprobarla y asimismo demostrar la vigencia de su pensamiento de cara a lo que también podemos identificar hoy como contrarrevolución neoliberal. 
Si Cueva entregó al pensamiento latinoamericano el horizonte teórico de un fenómeno que requiere ser estudiado a través de cada uno de los núcleos analíticos que él detectó, y que por sí mismos trazan una exquisita y flexible ruta metodológica, aquí, por razones de espacio, y sin afectar la visibilidad del fenómeno y el entramado de los núcleos que lo constituyen, no abundaremos en el tema del sentido común ni tampoco en lo concerniente a los conglomerados de la comunicación. Y ya que el pensamiento de Cueva se detuvo en 1992, pero no, desde luego, el fenómeno contrarrevolucionario, nos vemos también obligados a salir de su pensamiento y regresar oscilatoriamente a él. Así pues, tomando en cuenta que la lectura de aquellos núcleos puede realizarse de modo no lineal, consideramos necesario abordar antes que nada el asunto del darwinismo económico porque de lo contrario, la otra violencia referida al aluvión derechista, a la cruzada ideológica, no se comprendería como tal.

\section{ECONOMÍA DEL LUCRO Y DEL SUFRIMIENTO}

La ley general de la acumulación capitalista, explicada por Carlos Marx (2015, I-I: 546-636), nos demuestra que la concentración de la riqueza solamente es asequible si en la contraparte social incrementa simultáneamente la miseria. A sabiendas de que el reconocimiento epistemológico de las contradicciones desarrolladas durante el curso histórico del capital provienen no de un concepto interpretativo sino de una ley explicativa, en la fase contrarrevolucionaria, iniciada en los años ochenta, estas contradicciones tenderían a maximizase y presentarse de manera catastrófica en la vida social. Y si bien, en cuanto al manejo de cifras económicas lo más recomendable sería situarlas en términos de una comparación actualizada, es decir, redirigirlas hacia el momento contemporáneo de su aplicación, podemos con ello advertir que, no siendo este el rol característico de Cueva, los datos económicos que queremos usar como punto de partida no provienen del ecuatoriano sino de Pablo González Casanova.

Echando mano de diversas investigaciones cuantitativas realizadas por José Gandarilla, en 1998, González Casanova constató que las políticas neoliberales implementadas desde los ochenta aceleraron abruptamente las transferencias de excedentes de la periferia al centro del mundo. El excedente de 1 billón 364 mil millones de dólares, transferido entre 1992 y 1995, triplicó en esos años el excedente correspondiente a la de la fase 
del capitalismo monopólico, referida a los años transcurridos entre 1972 y 1981 (González Casanova, 2009: 173-174). Asimismo, de 1992 a 1995, según reportes de la Forbes, la fortuna total de los milmillonarios se duplicó, pasando de 565 mil millones a 1.1 billones de dólares. A 2013, la fortuna total de los milmillonarios alcanzó los 6.4 billones de dólares, es decir, desde 1995 se sextuplicó. ${ }^{1}$

A pesar de que esta cuantificación de extracción y superganancias nos permite conjeturar que el saqueo perpetrado durante la fase contrarrevolucionaria es equiparable al del capitalismo colonial, e incluso rebasarlo, a cuentas del Banco Mundial (BM), sin embargo, la realidad de las cosas es diferente, salvo que pongamos en cuestión sus métodos analíticos y arrojemos al basurero de las mentiras sus resultados. Según el documento Results 2013 del Banco, el porcentaje de la población que vive en los países en desarrollo con menos de 1.25 dólares al día se redujo de un $42.3 \%$ en 1990 a un $20.9 \%$ en 2010, es decir, en esos veinte años contrarrevolucionarios, según el $\mathrm{BM}$, se redujo a la mitad el índice de la pobreza extrema. A 2010, según el citado documento, 1.2 mil millones de seres humanos viven con menos de 1.25 dólares al día, y otros 2.7 mil millones de personas viven hasta con 4.00 dólares al día. Este último sector, a juicio del вм, "no es pobre pero sí vulnerable de caer en la pobreza" (wB, 2013: 5 y 12). ${ }^{2}$ Esta afirmación nos parece cruelmente encubridora. La línea definida en 4 dólares diarios o 1460 dólares anuales es equivalente al PIB per cápita de Tanzania -1440 dólares, a 2010- (PRB, 2012: 14), o equivalente al salario mínimo mexicano.

Aunque el umbral de 1.25 dólares propone medir al sector poblacional que vive en estado de indigencia, hambruna crónica e inanición, y no otras formas de pobreza que sí serían, con la indignación nuestra de decirlo, explotables para la acumulación de capital, el otro umbral de 4 dólares y con el cual el Banco cuantifica la vulnerabilidad, suprime y anula la experiencia dolorosa y el estado de supervivencia que atraviesan $2.7 \mathrm{mil}$

\footnotetext{
1 Cuenta propia a partir de datos publicados en su sitio web. Forbes, "The Worlds's Billonaires 25th Anniversary Timeline", [en línea], sitio oficial, s/fecha, dirección URL: http://www.forbes.com/special-report/2012/billionaires-25th-anniversary-timeline.html [consulta: 9 de febrero, 2014]; y Forbes, "The World's billionaires" [en línea], sitio oficial, s/fecha, dirección URL: http://www.forbes.com/billionaires/ [consulta: 23 de marzo, 2014]. Bajo el entendido que los reportes de la Forbes refieren al año anterior de cada publicación, los datos relacionados corresponden a los reportes originales de 1993, 1996 y 2014.

2 Traducción nuestra.
} 
millones de seres humanos que, antes de que el Banco los excluya de todo programa humanitario y social, tendrían que ser considerados y definidos como personas que objetivamente sufren pobreza no moderada y otras formas diversas de opresión.

Ahora bien, si el umbral de la pobreza no estuviese basado en la realidad económica de las naciones más pobres y estuviese por el contrario definida desde los parámetros de la economía estadounidense y sus altos niveles de consumo, los resultados serían lógicamente distintos. Bajo parámetros estadounidenses y situando la línea de la pobreza en 10 dólares al día, Martin Ravallion, Shaohua Chen y Prem Sangraula (2008: 3) calcularon que el $95 \%$ o más de la población de los países en desarrollo debería considerarse como pobre. Esta propuesta recuperaría el significado dramático que antes aludía al subdesarrollo, o bien, al Tercer Mundo, y que, desde luego, tras el aluvión derechista, que más adelante abordaremos, estos conceptos han sido borrados del mapa teórico a través del uso incesante de eufemismos como el de «economías emergentes», o también, "países en desarrollo».

El umbral de 10 dólares diarios es una propuesta original de Lant Pritchett. Si se agregaran 0.45 centavos a la línea estandarizada de 2.00 dólares, dice Pritchett, "500 millones de personas cambiarían de no pobre a pobre". ${ }^{3}$ Con precios de 1985 y del año 2000, Pritchett sitúa cuatro categorías de estimación poblacional: indigencia -por debajo de $\$ 1 / \mathrm{P} \$ 1.50-$, pobreza extrema -por debajo de $\$ 2 / \mathrm{P} \$ 3.00$ dólares-, pobreza global -por debajo de $\$ 10 / \mathrm{P} \$ 15$ dólares-, y sin pobreza -por encima de cualquier umbral de la pobreza-. Con base en una población mundial de 6.2 mil millones, Pritchett afirma que el $20.5 \%$ vive en estado de indigencia, el $26.3 \%$ en pobreza extrema, el $41.1 \%$ en estado de pobreza global, y sólo el $12.1 \%$ de la población mundial vive sin ningún tipo de pobreza. Su investigación arroja resultados catastróficos y darwinistas: un mil 271 millones viven en indigencia, un mil 630 millones 600 mil en pobreza extrema, y dos mil 548 millones 200 mil en pobreza global; sólo 750 millones 200 mil personas viven libres de pobreza (Pritchett, 2006: 8-16). En síntesis, el 87.9\% de la población mundial es pobre y el $12.1 \%$ no lo es.

Si la anterior división de la especie humana puede resultar exagerada, en realidad, ésta también se encuentra sugerida en los análisis de la riqueza. A cuentas del Instituto de Investigación del Credit Suisse, a 2013,

3 Traducción nuestra. 
la riqueza global ascendió a 240.8 billones de dólares, que para el caso el Instituto la calcula desglosada en cuatro sectores poblaciones conformando de ese modo su renombrada pirámide global de la riqueza. ${ }^{4}$ Con los datos que presenta el Instituto es posible afirmar que el $8.4 \%$ de la población adulta concentró, en 2013 , el $83.3 \%$ de la riqueza mundial, o al revés, el $16.7 \%$ de la riqueza se distribuyó en el $91.6 \%$ de la población. Tres años atrás, sin embargo, el reporte de la Credit Suisse de 2010 reveló que el $8 \%$ de la población adulta concentró el $79.3 \%$ de la riqueza mundial, o al revés, el $20.7 \%$ de la riqueza se distribuyó en el $92 \%$ de la población. ${ }^{5}$ De 2010 a 2013, los sectores más privilegiados incrementaron en promedio su población en un $9.71 \%$, pero su concentración total aumentó $30 \%$, mientras los sectores menos privilegiados incrementaron en promedio su población en un $4.65 \%$, pero la concentración total de su riqueza, en esos años, no aumentó ni disminuyó un solo centavo. No sería descabellado anticipar que antes de que concluya la segunda década de este siglo sepamos que la riqueza concentrada en el $1 \%$ de la población mundial sea mayor a la riqueza distribuida en el $99 \%$ restante. Esa es la tendencia contrarrevolucionaria de la economía del lucro y el sufrimiento.

En 1988, volviendo a Cueva, el ecuatoriano relató una anécdota en la cual dice que un colega suyo le "reprochó airadamente" sus "referencias al imperialismo": "Me parece estar escuchando las viejas arengas de los años sesenta» -le dijo el susodicho a Cueva-, «en la actualidad el concepto de imperialismo no tiene la menor utilidad teórica». Unos meses después,

4 La pirámide global de la riqueza de 2013, del cs (2013: 22), expone lo siguiente: el $41 \%$ (USD 98.7 billones) de la riqueza mundial está en manos del $0.7 \%$ (32 millones) de la población adulta que cuenta cada uno con más de 1 millón de dólares; el 42.3\% (USD 101.8 billones) de la riqueza está en manos del 7.7\% (361 millones) de la población adulta que cuenta cada uno con 100 mil a 1 millón de dólares; el 13.7\% (usd 33 billones) de la riqueza mundial está en manos del 22.9\% (1,066 millones) de la población adulta que cuenta cada uno con 10 mil a 100 mil dólares; y el 3\% (UsD 7.3 billones) de la riqueza mundial está en manos el $68.7 \%$ (3,207 millones) de la población adulta que cuenta cada uno con menos de 10 mil dólares.

5 La pirámide global de la riqueza de 2010, del cs (2010: 81), expone lo siguiente: el $35.6 \%$ (USD 69.2 billones) de la riqueza mundial está en manos del $0.5 \%$ ( 24.2 millones) de la población adulta que cuenta cada uno con más de 1 millón de dólares; el 43.7\% (USD 85 billones) de la riqueza está en manos del 7.5\% (334 millones) de la población adulta que cuenta cada uno con 100 mil a 1 millón de dólares; el 16.5\% (usD 32.1 billones) de la riqueza mundial está en manos del $23.5 \%$ (1,045 millones) de la población adulta que cuenta cada uno con 10 mil a 100 mil dólares; y el 4.2\% (USD 8.2 billones) de la riqueza mundial está en manos el $68.4 \%$ (3,038 millones) de la población adulta que cuenta cada uno con menos de 10 mil dólares. 
cuenta también Cueva, un filósofo español pretendió explicarle lo anterior: «Actualmente vivimos [...] la problemática de la posmodernidad; es decir, la de una época caracterizada por el pluralismo ideológico, por el respeto a todas la culturas; hemos entrado en una época de apaciguamiento político, asistimos al eclipse de las posiciones "fundamentalistas" y a su reemplazo por un estado de ánimo más bien lúdico y escéptico». Con estos dos relatos Agustín Cueva había iniciado su ponencia Vigencia y urgencia del Che en la era del neoconservadurismo que ya citamos, y en la cual y ante tales desaires, también preguntó: “¿Será verdad que la era del imperialismo ha terminado [...]?", ya que "la seductora imagen -mitad idílica, mitad decadente- de una posmodernidad lúdica y refinadamente escéptica, dista mucho de corresponder a los datos crudos de la realidad mundial." (Cueva, 2012c: 157-158).

\section{DEL ALUVIÓN DERECHISTA AL PENSAMIENTO ÚNICO}

Que se haya sumado la teoría posmoderna a la campaña contra la visión revolucionaria es algo que no pretendemos debatir aquí, aunque la alusión ameritaría ser introducida a pesar de que Agustín Cueva tampoco la identificó como corriente medular del aluvión derechista. En ese tenor diríamos tan sólo que, si bien, los procesos de desmantelamiento de la visión revolucionaria y de agudización de las contradicciones se desarrollaron simultáneamente y de modo ascendente, su correspondiente articulación tuvo que haber producido una nueva corriente de pensamiento distanciado o disociado de la realidad concreta y material. Aunque este distanciamiento constituye una marca anti-estructuralista y posmoderna, su causa política estaría implicada más bien en la construcción y dirección de un ambiente conceptual intolerante ante las categorías del pensamiento crítico, y asimismo, instrumentado para facilitar la conservación y estabilización de la economía del lucro a costa del sufrimiento que ésta produciría.

Ante la orientación del conocimiento producido y controlado por los intelectuales e investigadores integrados al aparato burocrático, o cobijados por éste, Cueva no tuvo otra opción que denunciarlos. Como lo revela él mismo, las corrientes de pensamiento que surgieron de tal relación política fueron la conservadora -encabezada por Mario Vargas Llosa y Octavio Paz, o Enrique Krauze- y la socialdemócrata -encabezada por Fernando Henrique Cardoso, pero ampliamente extendida en los trabajos de sociólogos y politólogos posmarxistas y posmodernistas-. Además 
de imputar cargos al antimarxismo de Norbert Lechner, Tomás Moulián, Angel Flisfisch, Manuel Antonio Garretón, José Aricó, Juan Carlos Portantiero y Marcelo Cavarozzi, o moderarlos en torno al eurocomunismo, el ecuatoriano propuso reflejar en un solo espejo político las corrientes de la derecha y de la denominada nueva izquierda, y contraponerlas así a la corriente "ligada al movimiento revolucionario latinoamericano", es decir, la del "pensamiento radical (antiimperialista y marxista)" (Cueva, 2012b: 182-185). Sin embargo, nuestro propósito no es desenredar los nudos teóricos en los cuales se abrazan entre sí las corrientes de la derecha y de la nueva izquierda, sino concentrarnos en el modo en que la interpretación sobre la vida concreta y material se separa de ésta, y que, en ese sentido o sobre dicha disociación, sostenemos que la mentira encubierta y no otra cosa constituye la norma discursiva y general del aluvión derechista.

Esta norma, manteniéndonos en los tiempos de Cueva, fue la que organizó el concepto de «encuentro de dos mundos», con el cual se «conmemoraron» los 500 años, no del desarrollo mundial capitalista -y ello, a meses de haberse desintegrado la Unión Soviética-, sino del proceso de genocidio y colonización que trajo consigo la invasión de Colón a territorio nuestro. Anulada la explicación histórica, el concepto negaba también la persistencia del racismo original, contenido y aplicado, aunque no «al pie de la letra», en los programas de esterilización forzada ${ }^{6}$ por ejemplo, que Alberto Fujimori y agencias estadounidenses preparaban en el Perú justo en los años en que la tesis de Miguel León-Portilla se debatía en el ambiente intelectual. ${ }^{7}$ Doscientos ochenta mil indígenas fueron este-

6 En el marco de las políticas denominadas "acciones de planeación familiar" o "programas contra la pobreza", y con el apoyo de agencias estadounidenses de cooperación internacional, se han registrado en los últimos 60 años acciones de esterilización forzada contra miles de mujeres en situación de marginalidad: contra puertorriqueñas en los años cincuenta; contra afroamericanas, latinas y amerindias, en EUA, durante las décadas de los sesenta y setenta; contra 280 mil mujeres indígenas en el Perú fujimorista mediante el "Plan de Salud Pública" en los años noventa. En México, estas prácticas han sido registradas desde los años setenta, e incluye, la esterilización condicionada al apoyo económico mediante el programa "Oportunidades". Según denuncias recibidas por la Organización Internacional del Trabajo (огт) y sesionadas en la Organización de Naciones Unidas (ONU), dichas prácticas se ejecutaron sistemáticamente bajo el Programa de Educación, Salud y Alimentación (Progresa), y el Programa de Capitalización del Campo (Procampo), incluyendo, entre éstas, esterilizaciones masculinas (Menéndez, 2009: 158-162).

7 Una respuesta al concepto de Miguel León-Portilla -y de Alberto Lozoya y José María Muriá- se encuentra en: O'Gorman (1987: 17-32). Otra más en Dussel (1994: 62), quien sostuvo que el concepto ocultaba "la dominación del "yo" europeo, de su "mundo", sobre el 
rilizadas en ese país, y sin embargo, el concepto triunfó con su nervio eufemístico esterilizando por su cuenta la necesidad de pensar la realidad social en los términos de capitalismo neocolonial, colonialismo interno, imperialismo, racismo y explotación; categorías, todos ellas, empleadas por el pensamiento crítico.

Así pues, en tanto el mundo se tornaba hegemónicamente capitalista, y las prácticas de racismo y exterminio contra los pueblos indígenas se programaban, y los españoles saludaban el 12 de octubre a sus Fuerzas Armadas, y los latinoamericanos, a la noción de su Raza, y el ambiente intelectual se convulsionaba ante el "encuentro de dos mundos», Agustín Cueva, un año antes de su fallecimiento, nos dejaría una respuesta inmejorable a "esa expresión tan tierna":

¿Se iba -se va- a celebrar exactamente qué? ¿La masacre de entre cinco y diez millones de aborígenes de estas tierras americanas? ¿El sometimiento a servidumbre de los sobrevivientes del genocidio, servidumbre cuyas secuelas subsisten pesadamente hasta nuestros días? ¿El racismo que igualmente perdura, como «herencia colonial», en los países de fuerte presencia indígena? ¿El inicio de un proceso de colonización, neocolonización y hegemonía imperialista que, actualmente, a raíz del llamado «fin de la historia», amenaza con reforzarse, revirtiendo una tendencia a la liberación que considerábamos sólidamente implantada a lo largo del siglo xx? (Cueva, 2009b: 142).

$\mathrm{Y}$ aunque Cueva expone cifras distantes a las que demuestran por ejemplo las investigaciones de Woodrow Borah y Sherburne F. Cook, ${ }^{8}$ en su respuesta cita un concepto que resulta fundamental para explicar la tendencia determinante de la contrarrevolución, es decir, el «fin de la historia». Planteado entre otros por Francis Fukuyama (1990), el fin de la historia consistía básicamente en que el mundo, a partir de la caída del bloque soviético, sería gobernado en su totalidad y dirigido por el (neo)

\footnotetext{
“mundo del Otro", del indio.". Años más tarde, León-Portilla insistía en que su tesis ofreció un nuevo enfoque al «descubrimiento" de América: "Ya no es la Europa egocéntrica que dice te descubrí, es la Europa que encontró maravillas aquí." (Celis y Cisneros, 2011: 40).

8 Según estudios de Borah y Cook (1962: 5-6), la guerra y las enfermedades provocaron la muerte de más de 22.5 millones de indígenas entre 1519 y 1607, sólo en el México central. Los autores lo califican como una de las peores catástrofes demográficas en la historia de la humanidad. Esta conclusión estadística forma parte de los llamados estudios maximalistas. Una comparación entre éstos y las investigaciones minimalistas se encuentra en McCaa (1999: 223-239).
} 
liberalismo hasta el fin de la humanidad. ${ }^{9}$ Tenga o no sustento epistemológico, el concepto, al margen de su implícita controversia, resguardaba más bien la agenda de su propia utopía negativa. Al negar de antemano futuros procesos de cambio, de transformación o de revolución, el concepto buscaba apagar, a través de la proyección totalitaria del neoliberalismo, el motor de la historia, es decir, las condiciones subjetivas que condujeran y sembraran la fractura o la discontinuidad del desarrollo histórico del capitalismo. Por eso, el fin de la historia se presentó como la viva expresión del sueño neoliberal, o ese que, como verdadera pesadilla, organizara la agenda necesaria para consolidar la acumulación acelerada de capital a través de la suspensión o el amortiguamiento controlado de la política contestataria y de la rebeldía social. Para ello, es decir, para encaminar la utopía negativa hacia su concreta materialización, era necesario introducir primero la visión derechista en el pensamiento social, y expulsar a través de ella la categoría de lucha de clases antes de ser controlada en la vida real. Al respecto, afirma Cueva:

El concepto de "lucha de clases", que ya empezaba a parecer de mal gusto, fue remplazado por la oposición "estado/sociedad civil", mientras el propio proceso de dominación política pasó a ser analizado en términos de simple "hegemonía". La explicación estructural era, a su turno, remplazada por los análisis culturalistas, de un nivel no siempre encomiable, por lo demás. (Cueva, 2012b: 191-192).

Que esta observación despierte polémica sobre todo en quienes, como nosotros, encontramos riqueza cualitativa en el concepto gramsciano de hegemonía, ${ }^{10}$ pero consideramos atractiva su crítica en torno a los estudios

9 Referencia correspondiente al ensayo ¿El fin de la historia? de Fukuyama, publicado originalmente en 1988 por la revista The National Interest. Este ensayo es el antecedente del célebre libro de Fukuyama (1992), el cual se publicó poco después de la crítica que realizó Cueva durante una ponencia en mayo de 1991.

10 En Gramsci, la hegemonía corresponde a la articulación entre sociedad civil -conjunto de organismos privados- y sociedad política o Estado, que cumple con la función de establecer dominio directo sobre el total social, y cuyos intelectuales se encargan "de las funciones subalternas", "del gobierno político" y "del consenso «espontáneo»", el cual "nace «históricamente» del prestigio (y por lo tanto de la confianza) derivado por el grupo dominante" (Gramsci, 1986: IV, 357). Cuatro años atrás, Agustín Cueva cuestionó que, si la hegemonía hablaba de la dirección intelectual y moral por parte del grupo dominante sobre el control del consenso de los dominados, el concepto no era incorrecto, decía, pero tampoco novedoso: "La ideología alemana, de Marx y Engels, está enteramente dedicada a demostrar que las ideas dominantes en una sociedad son precisamente las de la clase 
culturales, no significa que los reemplazos relatados por Cueva sean ajenos a la ola de sustituciones conceptuales que ha venido produciendo aquella norma discursiva que recurre la cruzada derechista para negar, disfrazar o justificar la violencia económica del capital. Si no lo planteamos así, la representatividad política del mundo que se interpreta en términos de economía de mercado, modernización del Estado, cultura del esfuerzo o globalización sin adjetivos, y no, por el contario, en términos de capitalismo, privatización de los bienes públicos, explotación o imperialismo, quedaría registrada, dicha representatividad, como producto espontáneo y natural de la evolución de la conciencia política e intelectual. Y aunque resultaría igualmente enriquecedor abundar sobre las distintas corrientes que componen la cruzada derechista, como las ya mencionadas, convendría en este caso, y para no perder de vista la característica coercitiva o epistemicida de su propia ofensiva, sintetizarlas en una sola forma de razón instrumental que, en 1995, Ignacio Ramonet íntegramente identificó como pensamiento único:

Atrapados. En las democracias actuales, cada vez son más los ciudadanos que se sienten atrapados, empapados en una especie de doctrina viciosa que, insensiblemente, envuelve cualquier razonamiento rebelde, lo inhibe, lo perturba, lo paraliza y acaba por ahogarlo. Esa doctrina es el pensamiento único, el único autorizado por una invisible y omnipresente policía de opinión (Ramonet, 1999: 4). ${ }^{11}$

El pensamiento único, pongámoslo así, se distingue por ser y propagar la visión contraria a la del pensamiento crítico. Concretamente situado este último en los espacios de producción de conocimiento, pero declarado como pensamiento anticapitalista, antiimperialista y anticolonialista, o también rebelde y activista, aquel otro, el único, es un pensamiento dedicado a anularlo y aislarlo de la vida científica y social. El pensamiento único, incompatible al crítico, recurre al entero aparato pedagógico, mediático y cultural existente para disciplinar y estandarizar la percepción y concepción política y moral de las contradicciones económicas y sociales, aprisionando, cercando y silenciando la mirada o la denuncia crítica ante aquéllas, y convocando así al resto de las miradas a identificarse con su mundo uniforme y uniformador.

materialmente dominante." (Cueva, 1984: 2). El ecuatoriano cuestiona la novedad del concepto, no su significado.

11 Publicado originalmente en Le Monde diplomatique, enero de 1995, bajo el título "La pensée unique". 
La policía de opinión a la que alude Ramonet tampoco es una metáfora de la represión simbólica sino de la organización corporativa que poseen las entidades imperialistas y la clase económica dominante para diseñar, producir, distribuir e imprimir sobre la conciencia general la señal dictatorial del pensamiento único. Producida y difundida por un puñado de pulpos mediáticos, y unas cuantas agencias de publicidad, de noticias e información, defendida a capa y espada por cientos de miles de investigadores e intelectuales agrupados en más de seis mil tanques neoliberales de pensamiento (think tanks), distribuidos en 182 países (GGTTI, 2013: 12), y vigilada su circulación en la red por agencias civiles, de inteligencia y de seguridad, o bien, descargada por estas últimas en campañas psicológicas de contrainsurgencia, ${ }^{12}$ la señal colonialista del pensamiento único explica, a nuestro juicio, por qué Agustín Cueva, en 1986, denunció el "brusco giro a la derecha de la gran mayoría de los intelectuales de Occidente", el cual produjo -nos dice pero siguiendo a Herbert Marcuse- el divorcio de la conciencia avanzada y la fuerza explotada (Cueva, 1987: 12).

Este divorcio contradictorio, que nos remite a la relación gramsciana de la coerción y el consenso, ${ }^{13}$ podría también ser esclarecido a través de dos formas articuladas de explotación; una, dirigida a la vida material, y otra, a la vida psicológica de los seres humanos. Es por demás conocido que Agustín Cueva mantuvo diferencias teóricas con Ruy Mauro Marini, sin embargo, y conviene recordarlo, el ecuatoriano rectificó en tiempo y en forma su posición contra una de las categorías centrales del sociólogo y economista brasileño (Cueva, 2012b: 200), es decir, aquella que nos indica que toda actividad laboral que se remunera por debajo de su valor corresponde a una superexplotación del trabajo (Marini, 1991: 41-42). Si toda fuerza que se tasa por debajo del consumo necesario para que el trabajador reponga su desgaste físico y mental produce no otra cosa que plusvalor, en ese sentido, y ante esa relación determinante de explotación, la otra, la segunda forma, desempeñaría por lo tanto la tarea de justificarla, pero la operación específica y concerniente de dicha tarea,

\footnotetext{
12 Nos referimos principalmente a las agencias The National Endowment for Democracy (NED), United States Agency for International Development (USAID) y National Security Agency (NSA). Este tema, el de las operaciones psicológicas, se encuentra ampliamente documentado con fuentes de primera mano por Tania Arroyo (2014), y explicado a través de modelos de propaganda y mecanismos inconscientes por Blanca Montoya (2010).

13 La relación entre la fuerza -coerción- y el consenso se encuentra desarrollada en Gramsci (1999, V: 13-443).
} 
ejecutada a través de los medios de comunicación, del cine, de la religión, de las escuelas o de la ciencia, corresponde en los términos originales de Ludovico Silva a la explotación de plusvalía ideológica, es decir, cuando "la parte no consciente de la energía psíquica de las gentes pasa a formar parte del capital ideológico imperialista, a sustentarlo, a preservarlo y a perpetuarlo." (Silva, 1982: 164).

Podemos entrever entonces que, articulada a la explotación de plusvalía material, esa segunda forma de explotación es la que produce precisamente el efecto de disociación del que hemos hablado, y que, valorándose éste en términos epistemológicos, culturales, discursivos o ideológicos, la explicación de la realidad social y sometida a la contrarrevolución neoliberal, en esos términos o desde esos ámbitos, se torna eufemística, artificiosa, ilusoria o mentirosa. Aunque esta forma de explotación psicológica se ilustraría de mejor manera analizando los modelos de propaganda y las campañas de desprestigio, o bien, los contenidos televisivos y hollywoodenses, diremos, para no ampliar en demasía la cuestión, que la policía de opinión, como organizadora del discurso neoliberal, constituye el pensamiento-espejo de los intereses oligárquicos e imperialistas de dominación. Esta policía, que se vale del aparato tecnológico existente para engañar, sacudir las cabezas, mercantilizar los corazones, esconder las causas y las consecuencias de la economía del lucro, acarrear electores a las urnas neoliberales, y propiciar una cultura de la ingenuidad y la deshonestidad, es la que a final de cuentas optimiza el curso ascendente de la contrarrevolución.

Las dos formas articuladas de explotación, sin embargo, no resuelven la problemática del fenómeno contrarrevolucionario ni tampoco explican la tendencia determinante que también queremos exponer. Tomando en cuenta la lupa bidimensional de la explotación, diremos también que, si la colonización del pensamiento único fue simultánea a la colonización de los intereses oligárquicos en las leyes nacionales, dicho entramado no pudo sino responder a la declaración de una guerra de clase sustentada, por un lado, en el proyecto epistemicida del conocimiento rebelde, y por el otro, en el proyecto de aniquilación del estado social, proteccionista y nacional. No en vano, González Casanova (2006: 15) señaló en 2006 que, entre los años en que se editó y reeditó su Sociología de la Explotación, el pensamiento neoconservador y el pensamiento crítico habían coincidido en la tarea de estigmatizar los conceptos de explotación y de lucha de clases; ambos, nos lo recalca, a espaldas de aquellas. Si hemos querido palpar 
la característica epistemicida de la cruzada derechista por haber destruido la visión revolucionaria, tendríamos igualmente que tasar en esos términos beligerantes a la política económica que confiscó a los pueblos toda forma de herencia concedida por sus revoluciones antecesoras.

\section{POLÍTICA ECONÓMICA DEL EXTERMINIO}

Con fines de subrayar la característica realmente coercitiva del proyecto contrarrevolucionario, es importante recordar que en dictadura no sólo se ejerció la custodia militar del neoliberalismo político-económico, sino también se impuso abruptamente lo neo del liberalismo, y cuyo significado central concierne a la organización de la vida social sin instituciones democráticas, sin Estados soberanos, sin derechos sociales, sin manifestaciones libres de represalias, y sin otras relaciones sociales que hayan invocado como veraz la vinculación entre el capitalismo y la democracia, a pesar de que la ley general de la acumulación la contradiga tácitamente y de origen.

Pero no resultó involuntario sino estratégico el ascenso del liberalismo a su modalidad neo, en el sentido en que, si bien, la teoría liberal había destinado la cuestión democrática -burguesa, desde luego- a la función reguladora del libre mercado, es decir, a su mano invisible, el neoliberalismo, en cambio, vino a revelar a la luz de sus actos el chantaje ideológico de lo anterior. Si el ideario neoliberal estaba dirigido a destrabar por completo la libertad de mercado -es decir, la violencia del capital-, a conseguir su autocracia y que se estableciera a su favor la dictadura política de las oligarquías, ese proyecto no hubiese adquirido desarrollo histórico y expansión mundial únicamente desde regímenes militares como los que originalmente lo impusieron, o desde la aplicación permanente de la fuerza bruta, ni tampoco hubiese obtenido éxito ideológico ni respaldo social sin el advenimiento de las tecnologías satelitales y digitales de la comunicación.

Y si bien, nos resulta congruente afirmar que, además de su fundamento político-económico, el neoliberalismo también es un sistema tecnológico, ideológico y cultural, la formación de su sentido común, ingenuo y deshonesto, no dependería únicamente de sustituciones conceptuales y lingüísticas, sino también políticas, y en específico, del reemplazo institucional de la dictadura por la democracia o su denominada transición a ella. Si la utopía neoliberal - utopía negativa- consistía en acelerar los 
procesos de acumulación de capital y controlar al mismo tiempo las condiciones subjetivas para separarlas de la ineludible resistencia social, la resistencia de las grandes mayorías afectadas, era necesario convencer a éstas de que dicho proceso, en el marco de la democracia, las beneficiaría. A pesar de recibir una serie de ataques por haberse opuesto a esa democracia sin calificativos, sin adjetivos y sin contenidos, Agustín Cueva, sin embargo, alcanzó a calificarla, adjetivarla y significarla como "democracia imperialista" (Cueva, 2012a: 167). El meollo del asunto lo sintetiza el historiador Ramón Oquelí, traído por Cueva (2012a: 168) de un artículo de Gregorio Selser:

La importancia de las elecciones presidenciales, con fraude o sin él, es relativa. Este es un país sometido. Las decisiones que le afectan se toman primero en Washington, luego en la jefatura militar norteamericana en $\mathrm{Pa}$ namá (Southern Command), después en la jefatura de la base norteamericana de Palmerola aquí en Honduras, enseguida en la embajada norteamericana en Tegucigalpa, en quinto lugar viene el jefe de las fuerzas armadas hondureñas, y apenas en sexto lugar aparece el presidente de la república. Votamos, pues, por un funcionario de sexta categoría en cuanto a nivel de decisión. Las funciones de presidente se limitan a la administración de la miseria y la obtención de préstamos norteamericanos. ${ }^{14}$

Si las decisiones presidenciales no son decisiones soberanas, o como lo expresa Selser en el título de su artículo, «se votó por un presidente, pero el que manda vive enfrente», la vigencia de las palabras que cita Cueva de Oquelí confirma la naturaleza imperialista de la democracia impuesta en Latinoamérica durante los años noventa. La complejidad del asunto radica en que, primero, el origen de dicha democracia responde a una condición histórica del capitalismo que la marca como sustituta de las dictaduras militares, y segundo, o en términos subjetivos, que la represión sistémica económica no se vive por igual si además de ésta se sufre la represión sistémica militar. Y aunque el proceso lineal del neoliberalismo conduce irremediablemente a la coexistencia de ambas formas de represión, Cueva, consciente de la diferencia cualitativa entre el terrorismo de estado y su democracia restringida, aún así, se preguntó

14 Cueva cita a Selser, Gregorio (1985); "Honduras a las urnas: se votó por un presidente, pero el que manda vive enfrente", Le monde diplomatique en español, año VII, no. 84, diciembre de 1985, p. 30. 
si uno de los éxitos de la política contrarrevolucionaria de que los latinoamericanos venimos siendo víctimas, sobre todo en su versión moderna de los diez o quince últimos años, no consiste precisamente en habernos llevado a percibir el mundo a la manera de aquel antihéroe de un cuento de Samuel Beckett que, simbólicamente echado a puntapiés de todos los hogares, todavía se alegra de que no lo persigan también en la calle para golpearle "delante de los transeúntes" y hasta agradece al cielo que sus opresores sean "gente correcta según su dios" (Cueva, 2012a: 168-169).

El ecuatoriano tenía en claro que las dictaduras militares y sus sustitutas transiciones a la democracia las había impuesto de principio a fin el imperialismo. La sustitución era preocupante porque si las primeras detuvieron reaccionariamente el avanzado proceso de lucha de clases -volvamos al Chile allendista-, las segundas, por el contrario, convencían a más de uno de que el proceso de aquélla había concluido con su triunfo. Con ayuda de la nueva izquierda derechizada, la propagación de este convencimiento precipitaría la desaprobación social contra la persistencia de las luchas anticapitalistas, antiimperialistas y anticolonialistas. Para Cueva, en las respuestas de aprecio y agradecimiento -consciente y no consciente- al opresor imperialista de siempre se mostraban las nuevas formas de sometimiento que trajeron consigo las transiciones a la democracia. Al ecuatoriano no le quedó otro camino que denunciar que ésta era desconfiable y limitada. No está en manos de los pueblos la decisión -afirma- sobre el sistema de propiedad, sobre las relaciones centro-periferia, sobre la estructura de nuestros ejércitos, ni tampoco nos consultan "si queremos o no que sigan existiendo los grandes monopolios" o "si debemos o no pagar la deuda externa" (Cueva, 2012a: 171-172).

Huelga decir que los procesos neoliberales, junto a otros aquí no señalados, son procesos condicionados según la realidad social e histórica de cada país, y por tal motivo, el proceso jamás avanzó de manera homogénea ni se impuso por las mismas vías. Pero que el ascenso contrarrevolucionario en América Latina no haya sido uniforme ni simultáneo tampoco significa que éste con el paso del tiempo no haya penetrado y madurado, salvo en honrosas excepciones, en la mayoría de los países de la región que, a su vez, renuevan la dictadura neoliberal a través del voto popular concedido a sus instancias partidistas.

Intentando explicar la psicología del fascismo, cabe recordar, Wilhelm Reich (1972: 32) se cuestionó "por qué la mayoría de los hambrientos no roban y por qué la mayoría de los explotados no van a la huelga". 
Nos parece oportuno redirigir el cuestionamiento y preguntarnos por qué la mayoría de los pueblos latinoamericanos siguen depositando su confianza en la política económica neoliberal, reeligiéndola, renovándola en las urnas y sellando de ese modo la condena de su opresión. Y aunque esta pregunta nos regresaría al tema de la explotación bidimensional, lo interesante del asunto es que Agustín Cueva fue quien identificó la política económica neoliberal como "política económica del fascismo" (Cueva, 1995: 82). Y si bien, no debatiremos aquí sobre la vigencia del concepto puesto que el fascismo es una categoría históricamente determinada, la relación con el neoliberalismo nos permite tentar el grado de violencia que, por la vía terrorista o por la vía parlamentaria, su política económica produjo en la vida social desde su instalación en la región.

Según Cueva (2013: 33), la política económica del fascismo en América Latina se caracterizó por los procesos de "desnacionalización de la economía”, de "desmantelamiento del sector capitalista (no monopolístico) de estado", de "centralización de capital", de "cancelación del estado «benefactor»", de "transformación promonopólica del agro", y de "pauperización absoluta de la clase obrera". Analizados en 1976 por el ecuatoriano, estos procesos no corresponden sino al marco jurídico de la política económica neoliberal, el cual, impuesto y desarrollado hasta la fecha, legalizó la extracción acelerada de capital, la liberación de importaciones, la ocupación del capital monopólico transnacional en los sectores productivos y comerciales, la exención de obligaciones fiscales para las grandes empresas, la venta de los bienes públicos, estratégicos y de seguridad social, la institucionalización del multipartidismo neoliberal, el control empresarial de la educación y el conocimiento, y la represión contra los sindicatos autónomos, los pueblos indígenas y el disentimiento social.

En otras palabras, la deformación de las constituciones nacionales derivadas de los movimientos revolucionarios nos revela por sí sola el sentido exterminador de la política económica neoliberal. La contrarrevolución de ese modo construye una forma civilizatoria de vida social marginada de toda herencia y visión revolucionaria. Sometida la realidad social a las relaciones legalizadas de explotación, y custodiadas éstas por las fuerzas imperialistas, la deformación oligopólica del estado nacional correspondería, en su contraparte, a la abolición prácticamente irreversible del derecho de los pueblos a vivir sin sufrimientos. Si en su tendencia determinante la contrarrevolución suprime las herencias revolucionarias y avanza en la línea del tiempo escribiendo su propia historia al margen de 
ellas, es decir, una antihistoria, en términos sociopolíticos, el sentido de su irreversibilidad es por demás preocupante, puesto que en él se asomaría también el modo fascistizante que le dio origen, y que hoy, en México, remodela su realidad social. Este asunto, sin embargo, lo abordaremos en otro momento.

\section{PARA FINALIZAR}

Después de más de 30 años de la guerra que identificó y contestó Agustín Cueva hasta los últimos días de su vida, la revisión latinoamericana sigue ubicando al ecuatoriano como crítico de la teoría de la dependencia y no como crítico de la contrarrevolución. Esta omisión sólo puede estar justificada si se toma en consideración que los procesos de cambio en Venezuela (1999), en Brasil (2003), en Argentina (2003), en Bolivia (2006), en Ecuador (2007), en Nicaragua (2007) y en Uruguay (2010), sumados a Cuba (1959), retardaron, interrumpieron o suspendieron democráticamente -cada uno en su forma particular- la neoliberalización de Latinoamérica. Sin embargo, según planes del Comando Sur de los Estados Unidos, el proyecto de neoliberalización presentará avances sustanciales hacia el año 2018, a razón, entre otras, porque dicho país necesita incrementar para la siguiente década sus reservas de petróleo y de gas natural en un $31 \%$ у $62 \%$ respectivamente (ussoutнсом, 2008: 6).

Frente al posible proceso de neoliberalización continental, el cual requeriría echar abajo el actual bloque bolivariano, el pensamiento crítico de Agustín Cueva, en ese sentido, resulta ser un referente indispensable para explicar las fuerzas que lo articularían. Porque los procesos de cambio -los procesos históricos- se cuidan antes de ser juzgados a la ligera o a la distancia - pensemos en Venezuela, Bolivia y Ecuador-, conviene agregar una cosa más. Para Cueva, el capitalismo se consolidó en América Latina durante el último tercio del siglo XIX. Se trata de un periodo marcado en particular por la fase imperialista del capitalismo mundial, pero también, por el surgimiento en América Latina de la alianza imperialista-oligárquica como "eje fundamental del desarrollo reaccionario del capitalismo" (Cueva, 2009a: 139). Esta alianza, siguiendo a Cueva, ahogó la nacionalización económica y política en la región, deterioró los modos locales de producción y permitió al capital monopólico succionar los excedentes y obtener superganancias ante lo cual la escasez original del capital local se perpetuó (Cueva, 2009a: 98). También, la alianza intervino en 
la deformación y reconversión de los estados nación en estados liberales oligárquicos, los cuales se encargaron de

forjar un marco jurídico-político adecuado a la realización de la acumulación originaria de capital, erigiéndose en una potencia suficientemente autoritaria como para vencer toda resistencia que los grupos afectados pudiesen ofrecer. (Cueva, 2009a: 134).

Si en dicho periodo reaccionario se refleja la contrarrevolución actual, la controversia estribaría por lo tanto en que esta última sugiere destruir los derechos sociales que emanaron de las revoluciones posteriores al último tercio del siglo xix. Debido al incontestable progreso tecnológico, mediático y armamentista del capitalismo, la contrarrevolución plantea avanzar imposibilitando o reprimiendo la restauración y regeneración revolucionaria de dichos derechos. Es decir, la contrarrevolución es un proceso de derechización que en lugar de saltar hacia atrás y sobre la línea del tiempo social, camina hacia adelante destruyendo cada una de las herencias revolucionarias, e impidiendo su futura regeneración en la vida social. Porque las condiciones objetivas están más que dadas, contamos con la esperanza de que los pueblos se decidan nuevamente a ser el motor de la historia, y se solidaricen organizados con aquellos que resisten ante la permanente amenaza de ser avasallados.

\section{BiBLIOGRAFÍA}

ARROYO, T. (2014); Seguridad nacional, terrorismo y telecomunicaciones: el impacto de la nueva estrategia hegemónica en la América Latina del siglo $X X I$, tesis para obtener el grado de Doctora en Estudios Latinoamericanos. México: unAm, pp. 1-369.

BORAH, W. y S. F. Cook (1962); “La despoblación en el México central en el siglo XVI", en Historia mexicana, vol. XII (Julio-Septiembre), pp.1-12.

CELIS, L. y J. CISNEROS (2011); "Miguel León-Portilla, el valor de las lenguas", en Cultura y Arte de México, 9, (Marzo), pp. 34-40.

CREDIT SUISSE (2010); “Global Wealth Databook”, Research Institute. Zurich: Credit Suisse (October), pp.1-129.

, (2013); “Global Wealth Report 2013", Research Institute. Zurich: Credit Suisse AG (October), pp.1-64.

CUEVA, A. (1984); “El fetichismo de la hegemonía y el imperialismo”, en Cuadernos Políticos, 38 (Enero-Marzo), pp. 31-39. 
CUEVA, A. (1987); "El viraje conservador: señas y contraseñas", en Revista A, VIII, 20, (Enero-Abril), pp. 11-27. (1995); "La fascistización del Estado en América Latina”, en R. M. Marini y M. Millán (comps.), La Teoría Social Latinoamericana, textos escogidos, t. III, La centralidad del marxismo. México: UnAM, Facultad de Ciencias Políticas y Sociales, pp.79-87.

, (2008); "El análisis posmarxista del Estado latinoamericano (1988)", en A. Moreano (comp.), Entre la ira y la esperanza y otros ensayos de crítica latinoamericana. Fundamentos conceptuales Agustín Cueva. Bogotá: Siglo del Hombre / CLACso, pp.201-222.

, (2009a); El desarrollo del capitalismo en América Latina. México: Siglo XXI Editores.

, (2009b); "Falacias y coartadas del V Centenario", en Revista Casa de las Américas, 257 (octubre-diciembre), pp.142-146.

, (2012a); "La democracia latinoamericana: ¿forma vacía de todo contenido?", en F. Tinajero (comp.), Agustín Cueva. Ensayos Sociológicos y Políticos. Quito: Ministerio de Coordinación de la Política y Gobiernos Autónomos Descentralizados, pp. 165-176.

, (2012b); "Las interpretaciones de la democracia en América Latina: algunos problemas", en F. Tinajero (comp.), Agustín Cueva. Ensayos Sociológicos y Políticos. Quito: Ministerio de Coordinación de la Política y Gobiernos Autónomos Descentralizados, pp. 177-219.

(2012c); "Vigencia y urgencia del Che en la era del neoconservadurismo", en F. Tinajero (comp.), Agustín Cueva. Ensayos Sociológicos y Políticos. Quito: Ministerio de Coordinación de la Política y Gobiernos Autónomos Descentralizados, pp. 157-164.

, (2013); “La política económica del fascismo”, en R. Baéz y A. Rosero (eds.), Autoritarismo y fascismo en América Latina, Agustín Cueva. Quito: Centro de Pensamiento Crítico (Serie: Cuadernos políticos núm. 2). Biblioteca Agustín Cueva, pp. 33-48.

DUSSEL, E. (1994); 1492. El encubrimiento del Otro. Hacia el origen del "mito de la modernidad”. La Paz: Plural Editores, Centro de la Información para el Desarrollo / CID.

FORBES “The Worlds's Billonaires 25th Anniversary Timeline”. www.forbes. com/special-report/2012/billionaires-25th-anniversary-timeline.html (9 de febrero de 2014). , (2014); “The World's billionaires”. www.forbes.com/billionaires/ (23 de marzo de 2014).

FUKUYAMA, F. (1990); “¿El fin de la historia?”, en Estudios públicos, 37, pp.5-31. , (1992); El fin de la historia y el último hombre. México: Planeta. 
GGTTI (2013); “2013 Global Go to Think Tank Index Report”, J.G. McGann (dir.); Think Tanks and Civil Societies Program. Philadelphia: University of Pennsylvania, pp.1-117.

GONZÁlEZ CASANOVA, P. (2006); Sociología de la explotación. Buenos Aires: CLACSO (Nueva edición corregida).

, (2009); “La explotación global”, en M. Roitman Rosenmann (comp.), De la sociología del poder a la sociología de la explotación: pensar América Latina en el siglo XXI / Pablo González Casanova. Bogotá: Siglo del Hombre Editores y CLACso, pp. 157-181.

GRAMSCI, A. (1986); Cuadernos de la cárcel, t. 4. México: Ediciones ERA. (1999); Cuadernos de la cárcel. Edición crítica del Instituto Gramsci, t. 5, Cuadernos 13-19. México: Ediciones ERA / Benemérita Universidad Autónoma de Puebla.

MARINI, R. M. (1991); Dialéctica de la dependencia. México: Ediciones ERA.

MARX, K. (2015); El Capital. Crítica a la economía política, t. I, libro I. El proceso de producción del capital. México: Fondo de Cultura Económica.

MCCAA, R. (1999); “¿Fue el siglo XVI una catástrofe demográfica para México? Una respuesta basada en la demografía histórica”, en Papeles de Población, 5, 21 (Julio-Septiembre), pp. 223-239.

MENÉNDEZ, E. (2009); "De racismos, esterilizaciones y algunos otros olvidos de la antropología y la epidemiología mexicanas”, en Salud Colectiva, 5, 2 (Mayo-Agosto), pp.155-179.

MONTOYA, B. (2010); El dominio mediático. México: Fantasmas.

O'GORMAN, E. (1987); "La falacia histórica de Miguel León Portilla sobre el «encuentro del Viejo y Nuevo Mundos»", en Quinto Centenario, 12, pp. 17-32.

POPULATION REFERENCE BUREAU (2012); "Cuadro de datos de la población mundial 2012”. Washington, D. C.: Population Reference Bureau (Octubre), pp.1-20.

PRITCHETT, L. (2006); "Who is Not Poor? Dreaming of a World Truly Free of Poverty", en The World Bank Research Observer, 21, 1 (Spring), pp. 1-23.

RAMONET, I. (1999); "El pensamiento único”, en INETemas, Publicación del Instituto de Estudios Transnacionales de Córdoba, año VI, 16 (Diciembre), pp. 4-5.

RAVALliON, M., S. Chen y P. Sangraula (2008); “Dollar a Day Revisited”, en Policy Research Working Paper 4620, Development Research Group (May). Washington, D.C.: The World Bank, pp.1-40.

REICH, W. (1972); Psicología de masas del fascismo. Madrid: Editorial Ayuso.

SILVA, L. (1982); Teoría y práctica de la ideología. México: Nuestro Tiempo. 
USSOUTHCOM (2008); "Command Strategy 2018. Partnerships for the Americas” United States Southern Command, pp.1-20. http://www.resdal.org/ ultimos-documentos/usa-command-strategy.pdf (4 de octubre de 2014).

WORLD BANK (2013); “Results 2013”. Washington, D. C.: World Bank, pp. 1-67. 